\title{
Denitrification as Influenced by Photosynthetic Oxygen Production
}

\author{
By H. W. JANNASCH* \\ Department of Bacteriology, University of Wisconsin, Madison 6, \\ Wisconsin, U.S.A.
}

(Received 30 December 1959)

\begin{abstract}
SUMMARY
An attempt was made to detect interaction between photosynthesizing algae and denitrifying bacteria by cultivating Chlorella sp. with Pseudomonas stutzeri. Denitrification was inhibited by illumination of the mixed culture after a dark period of $3 \mathrm{hr}$. It is suggested that immediate inhibition is due to the molecular oxygen produced by the suspended algae and distributed homogeneously in the culture. A delay of this inhibition may be caused by uptake of oxygen by the denitrifiers at a more rapid rate than its production by the algae. Thus, the quantitative aspects of this interaction depend upon the particular conditions of cultivation used. The ecological implications are discussed.
\end{abstract}

\section{INTRODUCTION}

In shallow highly productive lakes and estuaries the daily gaseous exchanges due to photosynthesis can often produce a zone of reducing conditions above the bottom. Such waters are characterized by the occasional elimination of oxygen deficiencies by the photosynthetic action of submerged plants. Consequently, a direct inhibition of anaerobic processes may occur when photosynthetic liberation of oxygen is possible in the same medium under the same conditions of growth.

A situation of this type was tested in vitro by cultivation of algae with a denitrifying bacterium which was found as a contaminant of algal cultures. The work was stimulated by the observation of vigorous gas production in liquid cultures of a Chlorella sp. still contaminated by bacteria, which had been accidentally stored in the dark for several days. The gas was found to consist of $\mathrm{CO}_{2}, 10-15 \%(\mathrm{v} / \mathrm{v}) \mathrm{N}_{2}$, and traces of $\mathrm{O}_{2}$ and $\mathrm{N}_{2} \mathrm{O}$. Nitrate, initially present in the culture at $0.3 \%(\mathrm{w} / \mathrm{v})$, disappeared in a period of about 14 days. The only hydrogen donor present and possibly used by the denitrifying micro-organisms must have been decomposing algal material. Addition of other hydrogen donors (e.g. peptone, yeast extract) vigorously accelerated the disappearance of nitrate. Shaking and aeration retarded, but did not prevent, the loss of nitrate and appearance of elementary nitrogen. The sensitivity of the denitrification to an accompanying algal photosynthesis was then studied.

Since the discovery of denitrification, its occurrence in the presence of oxygen has been discussed in many papers which often reported contradictory results.

* Present address: Institut für Mikrobiologie, Göttingen, Germany. 
Failure to detect an inhibition effect of molecular oxygen on denitrification was found to be due to the method of estimating the dissolved oxygen in liquid media on the basis of a supposed equilibrium with the gas phase. Having applied polarographic measurements of the dissolved oxygen during denitrification Skerman \& MacRae (1957 a) disproved the existence of such an equilibrium in cultures containing heavy suspensions of organisms and-implying the alternative use of molecular oxygen and nitrate as hydrogen acceptors for denitrifying bacteria-they concluded: 'It appears that the competition between oxygen and nitrate for the donor electrons so favors the oxygen that nitrate reduction only occurs when the supply of oxygen is inadequate to meet the demand.' In a study on denitrification and micro-zonal oxygen deficiencies in an aerated medium (Jannasch, 1960), denitrification was determined by measuring the molecular nitrogen and nitrous oxide liberated into the gas phase. According to the findings of Skerman, Lack \& Millis (1951) and Skerman \& MacRae $(1957 a, b)$, the formation of gaseous nitrogen compounds may serve as the indicator for the availability of molecular oxygen to denitrifying bacteria. By this means the influence of oxygen produced by photosynthesizing algae upon denitrification was studied and is described in the present paper.

\section{METHODS}

Organisms. A bacteria-free culture of Chlorella sp. was obtained by streaking a concentrated sample of water from Lake Mendota, Madison, Wisconsin, U.S.A., on mineral agar containing soil extract (Pringsheim, 1946), and by several subsequent transfers on this medium. A loopful from an active agar slope culture thus obtained was inoculated into $500 \mathrm{ml}$. liquid medium (Umbreit, Burris \& Stauffer, 1957); diluted tenfold, and the culture was aerated in wash bottles $\left(5 \%(\mathrm{v} / \mathrm{v}) \mathrm{CO}_{2}\right.$; Warburg, Burk, Schocken \& Hendricks, 1950) at $20^{\circ}$; light of about 1200 lux was supplied by fluorescent tubes. After 3 days the organisms in the culture were removed by centrifugation, washed, and suspended in $500 \mathrm{ml}$. fresh medium. The nitrate concentration in the medium was adjusted to $200 \mathrm{mg}$. $/ \mathrm{l}$., and $800 \mathrm{mg}$. yeast extract/l. was added. The initial concentration of algae was $c .200,000 / \mathrm{ml}$.

Pseudomonas stutzeri was isolated and purified by the method of van Niel \& Allen (1952) from algal cultures stored for several days in the dark (see above). Half of the bacteria used for inoculum were grown aerobically, the other half anaerobically, for $12 \mathrm{hr}$. at $20^{\circ}$ and subsequently filtered, washed, and suspended in a few ml. phosphate buffer ( $\mathrm{pH} 7 \cdot 0$ ). The initial density of viable bacteria in the culture was about $10^{6} / \mathrm{ml}$.

Cultivation. The cultivation of Chlorella sp. with Pseudomonas stutzeri was accomplished in a flat culture vessel connected with a gas-collecting burette and levelling bulb (Fig. 1, $C, G$ ). After inoculating the algal culture with the bacteria, helium containing $5 \%(\mathrm{v} / \mathrm{v}) \mathrm{CO}_{2}$ was bubbled through the liquid; a sterile cotton filter was used to sterilize the gas entering through tube $\boldsymbol{A}$. Most of the oxygen was swept out of the system by a continuous gas stream supplied for $20 \mathrm{~min}$. Then the volume of the gas phase was adjusted to $500 \mathrm{ml}$., and the system closed. The entire culture system was placed in a $20^{\circ}$ incubator in which it was illuminated as described. Since gaseous oxygen was not present in concentrations great enough to influence denitrification, circulation of the gas phase was not necessary. Gentle agitation of 
the culture with a magnetic stirrer (Fig. 1, M) was used to prevent sedimentation. Growth took place at somewhat reduced pressure (Fig. 1, R). The change of the gas volume was measured after adjustment to $760 \mathrm{~mm}$. mercury (Nilsson, 1941). Gas samples were taken after evacuation of tube $T$ and sampling bottle $S$, and were analysed with the mass spectrometer. After absorption of $\mathrm{CO}_{2}$, increase or decrease in volume of single gas components $\left(\mathrm{N}_{2}, \mathrm{O}_{2}, \mathrm{~N}_{2} \mathrm{O}\right)$ was calculated from the change of their proportions in the gas mixture, and from the change of the entire gas volume. Tests for hydrogen were made according to Milton \& Waters (1956). Nitric oxide was found by the method of Najjar \& Allen (1954) to be present in insignificant amounts and was subsequently neglected. When complete gas absorption was necessary, as for the detection of hydrogen and nitric oxide, a circulating system was used as illustrated by Jannasch (1960). Liquid samples for the determination of nitrate and nitrite were taken through tube $A$ with the aid of the levelling bulb; care was taken to avoid contamination of the culture.

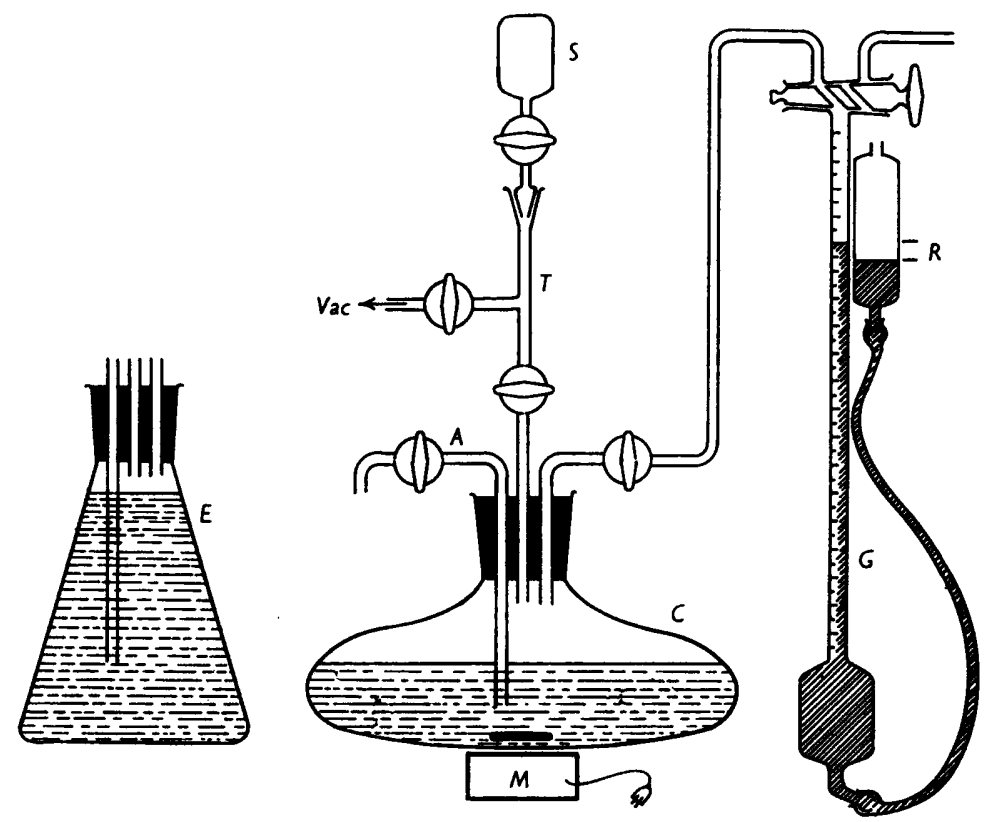

Fig. 1. Apparatus used (for explanation see text).

\section{RESULTS}

When the freshly inoculated medium was exposed to light after a $3 \mathrm{hr}$. dark period, oxygen was found to be liberated into the gas phase (Expt. 1; Fig. 2). The formation of elementary nitrogen, however, did not cease until about 20 min. after the oxygen concentration had reached an almost constant value of $0 \cdot 48 \%(v / v)$. Subsequently, the $\mathbf{N}_{2}$-concentration did not change during more than $2 \mathrm{hr}$. Then a slow and irregular increase in $\mathrm{N}_{2}$ was found, while the $\mathrm{O}_{2}$-concentration did not change significantly. Nitrous oxide (see Fig. 5) was here calculated as $\mathbf{N}_{2}$. The results of four parallel experiments showed a fair agreement, except for the last period of $\mathbf{N}_{2}$-formation. 
An attempt was made to simplify this experiment by splitting it into four modified experiments:

Expt. 2a. Chlorella inoculated only; conditions of cultivation unchanged.

Expt. 2b. Pseudomonas stutzeri inoculated only; conditions of cultivation unchanged.

Expt. 2c. Both organisms inoculated; no light but $20 \%(\mathrm{v} / \mathrm{v}) \mathrm{O}_{2}$ supplied after $3 \mathrm{hr}$.

Expt. 2d. Both organisms inoculated; $20 \%(\mathrm{v} / \mathrm{v}) \mathrm{O}_{2}$ supplied at the beginning of the experiment.

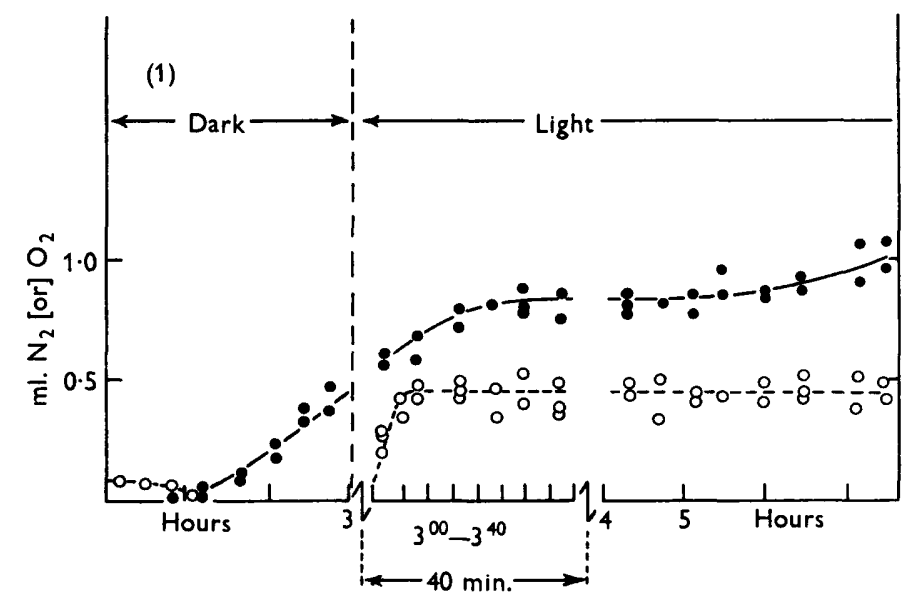

Fig. 2. Expt. 1:, $\mathrm{N}_{2} ; \bigcirc, \mathrm{O}_{2}$ (for explanation see text).

The results were as follows:

Expt. 2a. As in Expt. $10 \cdot 14 \%(\mathrm{v} / \mathrm{v}) \mathrm{O}_{2}$ was found in the gas phase at the beginning of the experiment; it decreased to about $0.08 \%(\mathrm{v} / \mathrm{v})$ during the dark period. When the first sample within the light period was taken 1 min. after illumination, the $\mathrm{O}_{2}$-concentration was as high as $1.8 \%(\mathrm{v} / \mathrm{v})$ and subsequently increased (Fig. 3, Expt. 2a).

Expt. 2b. The $\mathrm{O}_{2}$-concentration decreased to zero within about $90 \mathrm{~min}$. Starting after $40 \mathrm{~min}$., $\mathbf{N}_{\mathbf{2}}$-formation was unaffected by illumination, and did not cease until all nitrate was used up after $27 \mathrm{hr}$. (Fig. 3, Expt. $2 b$ ).

Expt. 2c. The $\mathrm{N}_{\mathbf{2}}$-formation was completely stopped a few minutes after addition of $20 \%(v / v)$ of $\mathrm{O}_{2}$ to the gas phase. Without any apparent lag, the $\mathrm{O}_{2}$-concentration decreased. The $\mathbf{N}_{2}$-formation continued when the $\mathrm{O}_{2}$-concentration was as low as $7 \cdot 1 \%$ (v/v) (Fig. 4, Expt. 2c).

Expt. 2d. The $\mathrm{O}_{2}$-concentration decreased from the beginning. After illumination, the decrease continued, but at a slower rate. $\mathbf{N}_{2}$-formation did not begin before an $\mathrm{O}_{2}$-concentration of $4.2 \%(\mathrm{v} / \mathrm{v})$ was reached after about $11 \mathrm{hr}$. As compared with Expts. $2 b$ and $2 c$, the $\mathrm{N}_{2}$-formation appeared to be depressed.

A few further observations may be noted. As far as the sensitivity of this volumetric method allowed, in Expt. $2 b$ the formation of 1 mmole $\mathrm{N}_{2}$ from 2 mmole nitrate was found, as described by Allen \& van Niel (1952). Calculating on the same 
basis, there was a small 'loss' of nitrate in Expts. 1, 2c and $2 d$. After $10 \mathrm{hr}$., this probable nitrate reduction by the algae did not exceed $4 \mathrm{mg}$. $\mathrm{NO}_{3}^{-} / \mathrm{l}$. or $2 \%(\mathrm{w} / \mathrm{v})$ of the nitrate initially present. Ammonia and amino-nitrogen, present in the yeast extract, appeared to be a sufficient nitrogen source for Pseudomonas stutzeri, and seemed to provide nitrogen for the algae as well.

Nitrous oxide was found up to $6.5 \%(\mathrm{v} / \mathrm{v})$ of the $\mathrm{N}_{2}$-concentration in the gas phase. While in Expt. 1 nitrite increased almost constantly up to $2.9 \mathrm{mg}$./l. (Fig. 5), nitrous oxide showed a distinct decrease between 5 and $8 \mathrm{hr}$. This is a correction of a preliminary non-reproducible observation (Jannasch, 1959) in which nitrous oxide was found to be formed during the dark period.

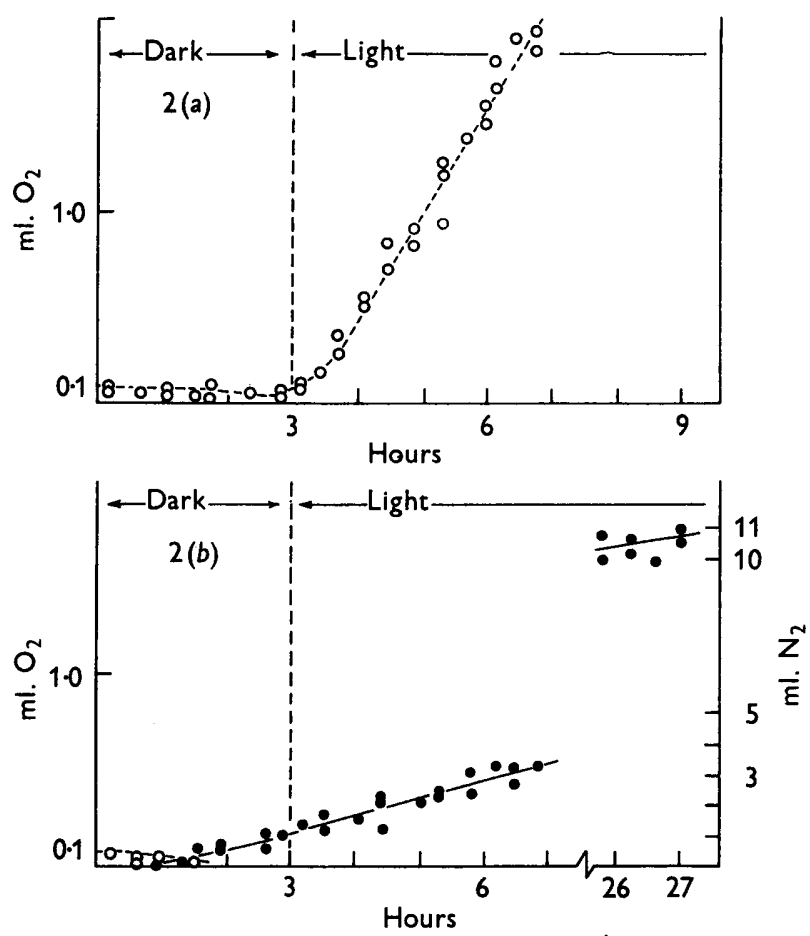

Fig. 3. Expts. $2 a, b: 0, \mathrm{~N}_{2} ; O, \mathrm{O}_{2}$ (for explanation see text).

The possible formation of elementary nitrogen from the reaction between nitrite and nitrogenous compounds reduced below the $\mathbf{N}_{2}$-level, as reported occasionally, was disproved for the conditions of cultivation used in the present study. After the addition of several ${ }^{15} \mathrm{~N}$-labelled $\alpha$-amino acids, no ${ }^{15} \mathrm{~N}_{2}$ was found in the gas phase.

After a week of cultivation the count of the algae in the simultaneous culture with Pseudomonas stutzeri was $20-30 \%$ higher than that of the pure culture of algae, and increased to $80-100 \%$ higher after 19 days.

\section{DISCUSSION}

Since no oxygen was found in the gas phase during the second and third hour of the dark period, and from consideration of Henry's law of partial pressures and the relative sensitivity of the mass-spectrometer test, the culture seemed to be deprived 
of dissolved oxygen. There is, however, no direct evidence to support this conclusion. Rabinowitch (1956), in reviewing the literature up to 1956, did not report any method for depriving an algal culture of oxygen other than by prolonged sweeping with oxygen-free gas in an open system. Since in the present experiments the first sample was taken $1 \mathrm{~min}$. after illumination, no induction period shorter
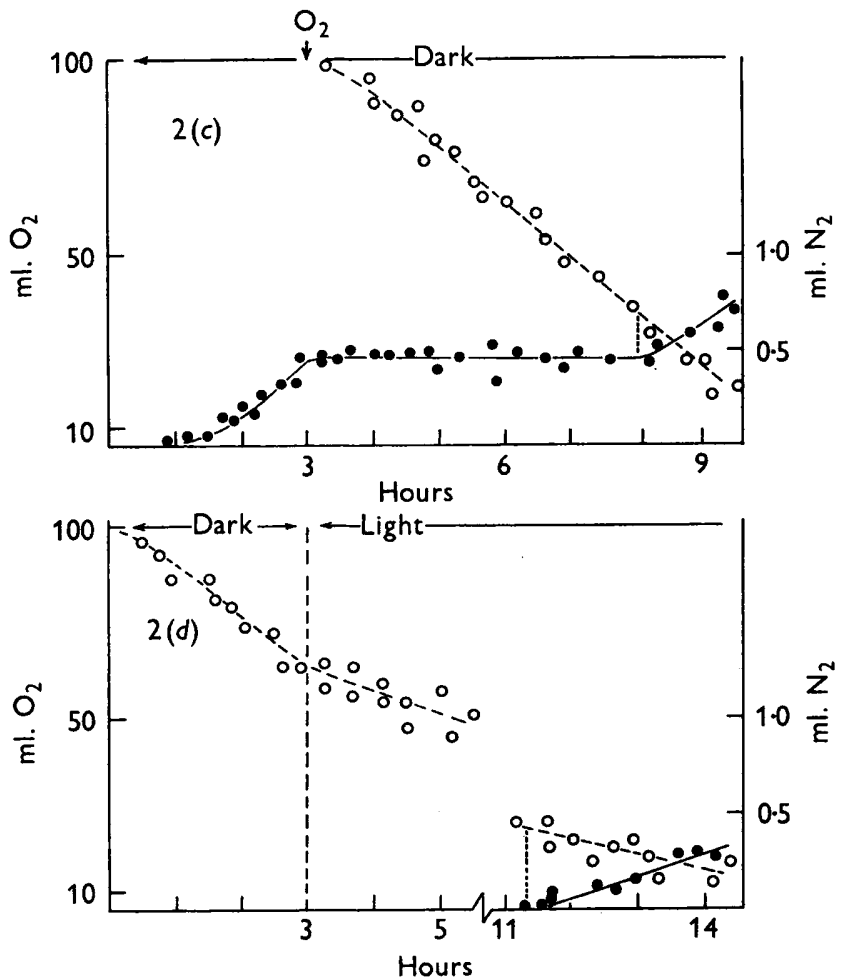

Fig. 4. Expts. 2c, $d$ : $\bullet, \mathrm{N}_{2} ; \mathrm{O}, \mathrm{O}_{2}$ (for explanation see text).

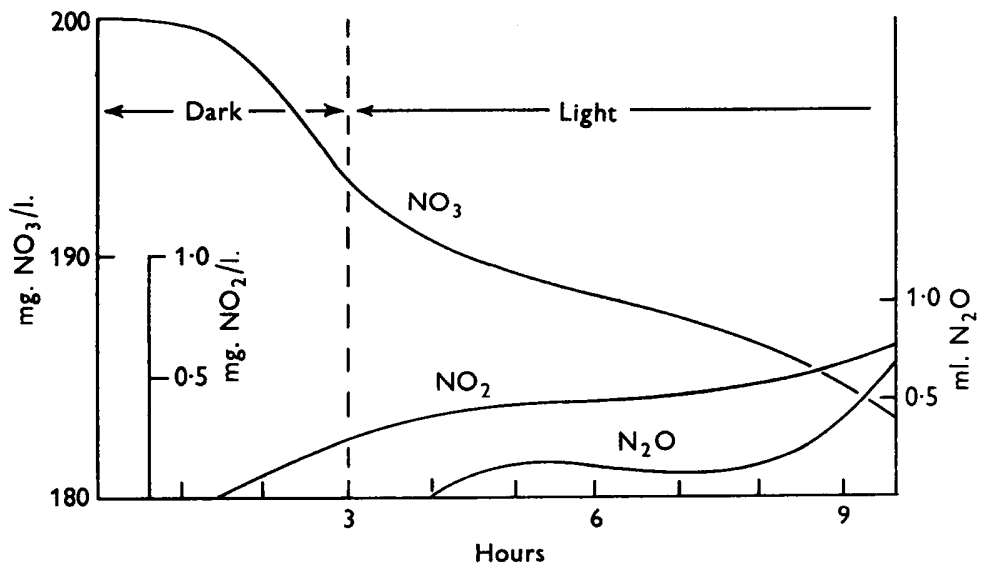

Fig. 5. Transformation of inorganic nitrogen in Expt. 1. 
than 1 min. could be determined. The amount of oxygen liberated at that time appeared to be slightly higher in Expt. $2 a$ than in Expt. 1.

Two related applications of physiological tests may be considered. Oxygen production by green algae was observed in the classical experiments of Engelmann (1881), who used semi-anaerobic conditions with motile $\mathrm{O}_{2}$-requiring bacteria as an indicator. Harvey (1928), using luminous bacteria, found that oxygen was produced by algae under completely anaerobic conditions within a second after the beginning of illumination. The similarities of photosynthesis in green plants and in purple bacteria led to the notion that oxygen is not necessary for this process; this aspect was presented by Franck (1953), and by Arnon, Whatley \& Allen (1957).

On the other hand, inhibition of oxygen production following anaerobic incubation in the dark, has frequently been observed. It was claimed by Franck, Pringsheim \& Lad (1945), and by Pratt, Oneto \& Pratt (1945) that such inhibition was caused by changes in $\mathrm{pH}$ value due to the accumulation of products of fermentation. With Chlorella Noack, Pirson \& Michels (1939) showed that neutralization as well as aeration removed the anaerobic inhibition; the oxidizable substance was unknown. Within periods of cultivation used in the present experiments, Chlorella has not been found to be adaptable to photo-reduction. No hydrogen was liberated as tested in Expt. 1.

The experiments showed clearly that the oxygen produced by the algae inhibited the formation of $\mathrm{N}_{2}$ from nitrate by Pseudomonas stutzeri. The quantitative aspects of this interaction, however, are believed to be influenced by the particular cultural conditions. The relative high concentration of readily oxidizable organic matter is responsible for the fact that the $\mathrm{O}_{2}$-uptake by the bacteria exceeds considerably the $\mathrm{O}_{2}$-production by the algae. Within the first $20 \mathrm{~min}$. of the light period, oxygen was produced by the algae and subsequently used as a hydrogen acceptor along with nitrate. After 20-30 min., oxygen seemed to replace nitrate until denitrification stops completely. Whether this delay of the complete inhibition of $\mathrm{N}_{2}$ formation was due to a slow increase of $\mathrm{O}_{2}$-production is not apparent. The appearance of oxygen in the gas phase does not reflect the true rate of $\mathrm{O}_{2}$-production but only that small fraction which 'escapes' into the gas phase before being consumed by the bacteria. The fact that a constant $\mathrm{O}_{2}$-concentration in the gas phase is reached in Expt. 1 shortly after illumination, supports the assumption that an equilibrium has been formed between liberation and re-absorption of oxygen by the liquid phase.

The beginning of the $\mathrm{N}_{\mathbf{2}}$-formation occurred in the presence of quite different $\mathrm{O}_{2}$-concentrations, depending apparently upon whether oxygen was supplied in the gas phase or produced by the suspended algae. According to Skerman's conclusions (see introduction) this is to be expected if the algae actually provide a more or less homogeneous distribution of the oxygen produced. Measuring the dissolved oxygen under the most favourable conditions for its uniform distribution, Skerman et al. $(1957 b)$ found $0.2 \mathrm{mg}$. $\mathrm{O}_{2} / \mathrm{l}$. sufficient to inhibit denitrification completely. When, however, oxygen was determined in the gas phase (Sacks \& Barker, 1949), only a partial inhibition of denitrification was found at $\mathrm{O}_{2}$-concentrations as high as 4-5\% (v/v, c. $2.0 \mathrm{mg}$./1.). This implies the existence of a gradient in oxygen concentration from the gas phase to the liquid phase, depending upon the rate of oxygen uptake in the latter. When oxygen is supplied directly into the liquid phase, 
as in the case of suspended algae under illumination, a lower oxygen-percentage in the gas phase must appear as the limiting concentration for denitrification.

The role of inadequate oxygen supply in determining the inhibitory effect of molecular oxygen on denitrification was studied by Collins (1956) and Fedorov \& Sergeeva (1957). Following the recommendations of these workers, a more vigorous agitation and culture vessels of different shape (providing a smaller liquid surface; Fig. 1, $E$, present paper) were used in repeating Expt. 1. No marked influence on the rate of inhibition was then found. This was not surprising since the oxygen, liberated into the gas phase, was below the inhibitory concentration. These results show that the proposed interaction between photosynthesizing algae and denitrifying bacteria exists in simultaneous culture. In the natural habitat, several additional factors may operate to change the quantitative aspects.

My thanks are due to Professor W. B. Sarles, University of Wisconsin, and to Dr F. J. Talling, Freshwater Biological Association Laboratory, Windermere, England, for helpful criticism of the manuscript. For help in using the massspectrometer, I am indebted to Professor R. H. Burris and Dr Lee Wang, Department of Biochemistry, University of Wisconsin, U.S.A. The work was supported in part by a grant from the Wisconsin Alumni Research Foundation administered by the Research Committee, Graduate School, University of Wisconsin.

\section{REFERENCES}

Allen, M. B. \& van Niel, C. B. (1952). Experiments on bacterial denitrification. J. Bact. 64, 397.

Arnon, D. I., Whatley, F. R. \& Aluen, M. B. (1957). Assimilatory power in photosynthesis. Science, 127, 1026.

Coluins, F. M. (1956). Bacterial denitrification in shaken cultures. Enzymologia, 17, 291.

Engelmann, T. W. (1881). Neue Methode zur Untersuchung der Sauerstoffausscheidung pflanzlicher und thierischer Organismen. Pfliig. Arch. ges. Physiol. 25, 285.

Fedorov, M. V. \& Sergeeva, R. V. (1957). The effect of oxidation-reduction conditions of the medium in the rate of nitrate reduction by denitrifying bacteria. Microbiology, Moscorv, 26, 137.

Franck, J. (1953). Participation of respiratory intermediates in the process of photosynthesis as an explanation of abnormally high quantum yields. Arch. Biochem. Biophys. 45, 190.

Franck, J., Pringsheim, P. \& Lad, D. T. (1945). Oxygen production by anaerobic photosynthesis of algae measured by a new micro-method. Arch. Biochem. 7, 103.

Harvey, E. N. (1928). Photosynthesis in absence of oxygen. Plant Physiol. 3, 85.

JANNASCH, H. W. (1959). Interactions between algae and denitrifying bacteria in vitro. Bact. Proc., 41.

JANNASCH, H. W. (1960). Versuche über Denitrifikation und die Verfügbarkeit des Sauerstoffes in Wasser und Schlamm. Arch. Hydrobiol. 56, 355.

MrLton, R. F. \& WATERs, W. A. (1955). Methods of Quantitative Microanalysis, p. 526. London: Arnold.

NaJjar, V. A. \& Aluen, M. B. (1954). Formation of $\mathrm{N}_{2}, \mathrm{~N}_{2} \mathrm{O}$, NO by extracts of denitrifying bacteria. J. biol. Chem. 206, 209.

Niel, C. B. van \& Aluen, M. B. (1952). A note on Pseudomonas stutzeri. J. Bact. 64, 413.

Nilsson, R. (1941). Methoden der Fermentforschung, p. 2150. Leipzig: Thieme.

Noack, K., Pirson, A. \& Mrchels, H. (1939). Zur Kenntnis der Assimilationshemmung nach Sauerstoffentzug bei Grünalgen. Naturwissenschaften, 27, 645.

Pratt, R., Oneto, J. F. \& Pratt, J. (1945). Studies on Chlorella vulgaris. X. Influence of the age of the culture on the accumulation of chlorellin. Amer. J. Bot. 32, 405 . 
Pringsheim, E. G. (1946). Pure Cultures of Algae. Cambridge University Press.

Rabinowitch, E. I. (1956). Photosynthesis and related processes, vol. 2, part 2. New York: Interscience Publishers.

SaCKs, L. E. \& Barker, H. A. (1949). The influence of oxygen on nitrate and nitrite reduction. J. Bact. 58, 11.

Skrrman, V. B. D., Lack, J. \& Miruis, N. (1951). Influence of oxygen on the reduction of nitrate by a Pseudomonas sp. in the growing culture. Aust. J. Sci. Res. B 4, 511.

Skerman, V. B. D. \& MACRAE, I. C. $(1957 a)$. The influence of oxygen on the reduction of nitrate by adapted cells of Pseudomonas denitrificans. Canad. J. Microbiol. 3, 216.

Skerman, V. B. D. \& MacRae, I. C. (1957b). The influence of oxygen availability on the degree of nitrate reduction by Pseudomonas denitrificans. Canad. J. Microbiol. 3, 506.

Umbreit, W. W., Burris, R. H. \& Stauffer, J. F. (1957). Manometric Techniques. Minneapolis: Burgess Publishers.

Warburg, O., Burk, D., Schocken, V. \& Hendricks, S. B. (1950). The quantum efficiency of photosynthesis. Biochem. Biophys. Acta, 4, 335. 